\title{
Identificação de competências docentes para o uso do ABP no ensino de química
}

\author{
Identificatin teachers skills for use PBL teaching of chemistry \\ V. A. S. Alves ${ }^{1}$; D. R. M. Costa ${ }^{1 *} ;$ V. W. B. Martins ${ }^{2}$ \\ ${ }^{1}$ Centro de Ciências Sociais e Educação, Campus Universitário de Marabá, 68503-120, Marabá-Pará, Brasil \\ ${ }^{2}$ Centro de Ciências Naturais e Tecnologia, Campus Universitário de Marabá, 68503-120, Marabá-Pará, Brasil \\ *danymont@uepa.br \\ (Recebido em 08 de abril de 2016; aceito em 04 de maio de 2016)
}

\begin{abstract}
Muitas críticas ao ensino tradicional referem-se à ação passiva do aprendiz que frequentemente é tratado como mero ouvinte das informações que o professor expõe. Esta pesquisa objetivou identificar quais as competências necessárias aos docentes do Ensino de Química para utilização da metodologia da ABP. O estudo foi realizado com uma amostra de 2 (dois) docentes e 27 (vinte e sete) discentes, onde aplicou-se um questionário estruturado com análise de 9 competências desejáveis para o uso da ABP no Ensino de Química. Os dados foram tratados e mensurados de acordo com a média das respostas dos discentes, comparando com as respostas dos docentes, afim de identificar quais competências devem ser potencializadas. Os resultados apresentados em gráficos apontam que as competências a serem potencializadas no docente A são: análise crítica, tomada de decisão consensual e gerenciamento de conflito; e as competências a serem potencializadas no docente B são: condução de reunião, resolver problemas e tomada de decisão consensual. As competências abordadas como falhas no trabalho mostram as dificuldades estruturais, profissionais e pessoais de cada docente avaliado, criando um ciclo de problemas absorvidos podendo ser solucionados através do uso da ABP. Conclui-se que é necessário um treinamento com o corpo docente para a adoção do método e que precisam ser potencializadas as competências identificadas como prioridades a serem desenvolvidas. A quebra de cultura e a aceitação de uma nova forma de abordagem do ensino por parte dos discentes e docentes será o primeiro passo para a mudança.

Palavras-Chave: Docência, Habilidades, Aprendizagem.
\end{abstract}

Many criticisms of traditional teaching refer to passive learner action that is often treated as mere listener of information the teacher explains. This research aimed to identify the skills needed for the teaching of chemistry teachers for use of problem based learning methodology. The study was conducted with a sample of two (2) teachers and 27 (twenty seven) students, which was applied a structured questionnaire with analysis of 9 desirable skills for the use of PBL in teaching chemistry. The data were processed and measured according to the average of the responses of students, compared with the responses of teachers in order to identify which skills should be maximized. The results presented in graphs show that the competencies to be leveraged in teaching A are: critical analysis, consensual decision-making and conflict management; and skills to be potentiated in teaching $\mathrm{B}$ are: meeting driving, solve problems and consensual decision-making. The skills addressed as failures at work show the structural difficulties, professional and personal of each rated teaching, creating a cycle of problems absorbed by the method can be solved through the use of PBL. We conclude that training is required with the faculty to adopt the method that needs to be enhanced the skills you identify as priorities for development. Breaking culture and the acceptance of a new teaching method by students and teachers will be the first step towards change.

Keywords: Teachers, Skills, Learning. 


\section{INTRODUÇÃO}

Para Gil [1] as aulas expositivas/atividades experimentais respondem a questionamentos aos quais os alunos nunca tiveram acesso, tornando isso algo novo, porém, que não pode se sobressair demais para tornar-se algo cansativo como encontramos nos meios tradicionais.

Por isso é de grande importância identificar quais são os impedimentos encontrados no cotidiano escolar para realização das aulas experimentais, dentre eles encontram-se diversos fatores, tal como a falta de laboratórios.

Para Melo [2] o construtivismo é considerado a maior contribuição teórica para o método de Aprendizagem Baseada em Problemas (ABP), porque "se fundamenta no princípio de que os aprendizes não copiam nem absorvem ideias do mundo exterior, mas constroem seus conceitos por meio da observação e experimentação ativa e pessoal". O método (ABP), conhecido em outros países como Problem Based Learning (PBL), que surgiu no século passado, no final da década de sessenta, na Escola de Medicina da Universidade de McMaster em Ontário, Canadá, e que tinha como finalidade propiciar aos seus alunos o contato com problemas reais bem como a aprendizagem dos conteúdos pertinentes à área [3].

Segundo Ribeiro [4], o método Aprendizagem Baseado em Problemas (ABP) é considerado efetivo para ajudar o estudante a aprender a aprender, porque sempre o desafia a desenvolver a habilidade de pensamento crítico, de analisar, de discutir, de selecionar e de usar recursos de aprendizagem apropriados para soluções de problemas, de forma integrada e organizada, permitindo sedimentação de informações capazes de serem recapituladas rapidamente e aplicadas em situações futuras. A ABP pode ser considerada uma das mais excitantes e eficientes opções de educação que tem aparecido nos últimos trinta anos.

Nesse método, o aluno é levado a identificar o problema, procurar informações, analisar alternativas, levantar hipóteses, encontrar possíveis soluções, fazer o julgamento destas e, a partir disso, chegar a uma tomada de decisão. Por fim, ele utiliza a argumentação e a persuasão para convencer os demais colegas de que a sua solução é a mais viável [5].

No entanto, segundo Guimarães [6], essa metodologia não deve ser pautada nas aulas experimentais seguida como um roteiro, fazer ciência, no campo científico, não é ateórico. Ao ensinar ciência, no âmbito escolar, deve-se também levar em consideração que toda observação não é feita num vazio conceitual, mas a partir de um corpo teórico que orienta a observação. Além disso, quando o experimento é realizado com a intenção de que os alunos obtenham os resultados esperados pelo professor, não há problema algum a ser resolvido, e o aprendiz não é desafiado a testar suas próprias hipóteses.

O objetivo deste trabalho foi identificar quais as competências docentes a serem potencializadas que são necessárias para utilização da ABP no Ensino de Química em uma Instituição de Ensino Superior.

\section{MATERIAIS E MÉTODOS}

O estudo foi desenvolvido na Universidade do Estado do Pará, Campus de Marabá, presente há 20 anos no estado, com laboratórios de química em seu prédio, fazem parte de um grupo que busca favorecer/fortalecer o ensino. A pesquisa foi realizada com 27 discentes da turma de licenciatura em ciências naturais com habilitação em química e com dois docentes da Universidade.

Esta pesquisa abordará a tentativa de quantificar em gráficos a opinião de dois docentes em relação as suas práticas pedagógicas desenvolvidas e suas competências, em comparação à opinião dos discentes que vivenciaram o método $\mathrm{ABP}$. 
Realizaram-se pesquisas em livros, artigos e dissertações de mestrado, com intuito de embasar a pesquisa sobre os temas envolvidos no estudo. Após o levantamento o bibliográfico, por meio de questionários foi feito levantamento sobre a competência de cada docente em suas metodologias, bem como, da opinião de cada discente pertencente à turma de ciências naturais sobre os métodos abordados pelos docentes.

Para a realização do tratamento dos dados utilizou-se o programa Microsoft Excel 2007, nos gráficos e tabelas os dados referente aos docentes é representada por "eu" e dos discentes por "os outros".

\section{RESULTADOS E DISCUSSÃO}

De acordo com a Figura 1, a falta de análise crítica que é evidenciada no docente $\mathrm{A}$, não é um fator positivo ao docente que deseja utilizar o método ABP. Segundo Costa [7], ensinar os estudantes a argumentar cientificamente é, hoje, um objetivo pedagógico prioritário e treiná-los para argumentação é permitir-lhes ver que a construção do conhecimento científico é um processo em trânsito, no qual as ciências são questionadas e, muitas vezes, mudadas ou revistas. Tomada de decisão consensual e gerenciamento de conflitos também são pontos a serem trabalhados.

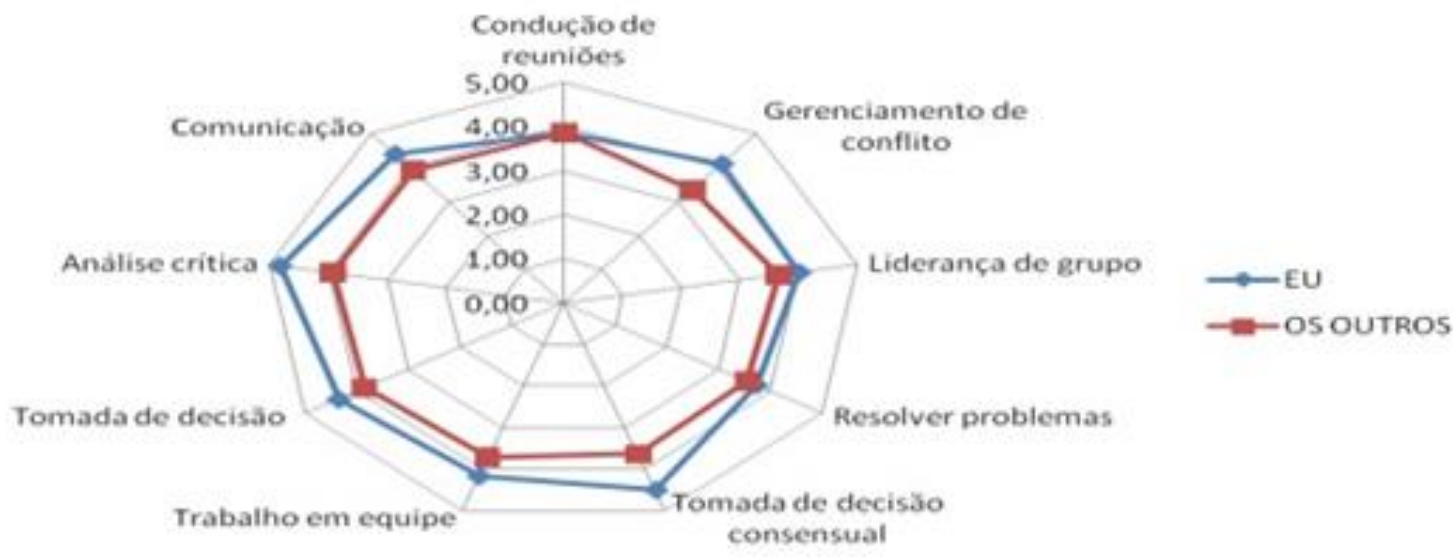

Figura 1. Média das Avaliações de competências docente A

Para Andrade [8], a proposta não é somente mostrar os erros e sim tentar expor que uma simples autoanalise pode transformar o tradicional em algo funcional.

Na Tabela 1, a habilidade "Tomada de decisão consensual" apresentou um percentual favorável de 4,50 para o docente A na utilização do método ABP, diferentemente do docente B que foi de 3,65. Sobre essa habilidade, segundo Santos; Mortimer [9] afirmam que a tomada de decisão em uma sociedade democrática pressupõe o debate público e a busca de uma solução que atenda ao interesse da maior parte da coletividade.

Tabela 1. Resumo das avaliações - docente A

\begin{tabular}{lrc}
\hline TÓPICOS ABORDADOS & EU & OS OUTROS \\
\hline Condução de reuniões & 3,86 & 3,86 \\
Gerenciamento de conflito & 4,11 & 3,35 \\
Liderança de grupo & 4,00 & 3,66 \\
Resolver problemas & 3,71 & 3,55 \\
Tomada de decisão consensual & 4,50 & 3,65 \\
Trabalho em equipe & 4,17 & 3,73 \\
Tomada de decisão & 4,36 & 3,86 \\
Análise crítica & 4,83 & 3,93 \\
Comunicação & 4,40 & 3,93 \\
\hline
\end{tabular}


Para o docente B (Figura 2), de acordo com os resultados do gráfico, as competências a serem potencializadas para o uso da ABP são: condução de reuniões, resolução de problemas e tomada de decisão consensual. Vale ressaltar, que todas as competências analisadas deram divergência considerável entre o que o docente julga possuir e qual a percepção dos discentes com relação às competências do docente.

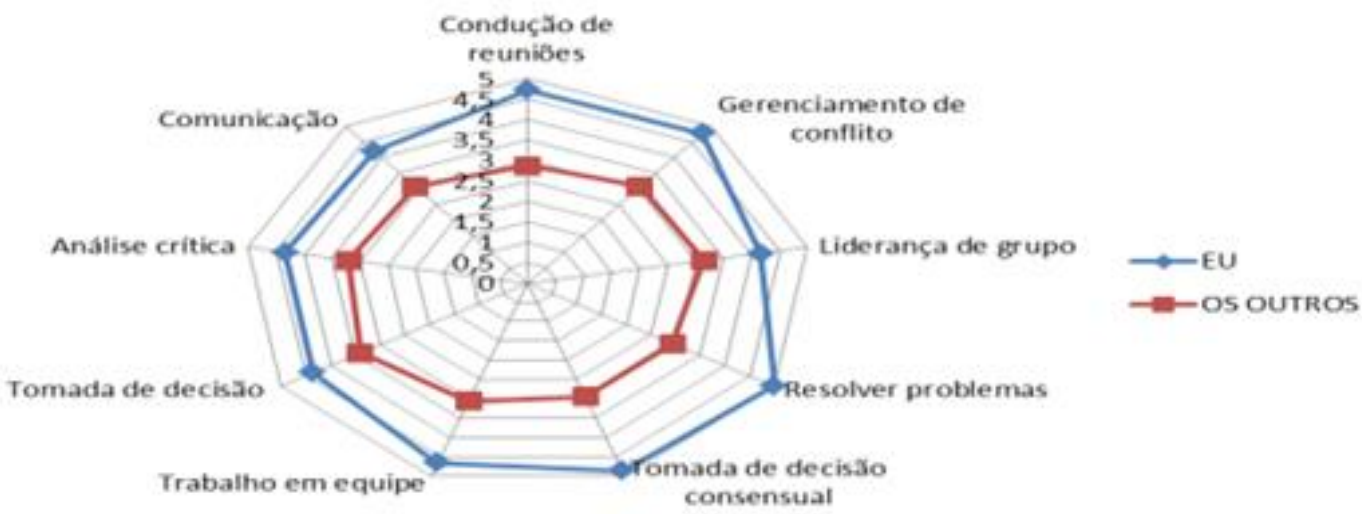

Figura 2. Média das avaliações de competências docente B.

Segundo Macambira [10] "A comunicação é um ato próprio da atividade psíquica, que deriva do pensamento, da linguagem.". A troca de mensagens verbal ou não verbal permite ao indivíduo influenciar os demais e ser influenciado, papel mais que fundamental dentro de uma IES ou de qualquer centro de ensino, expressar-se de uma forma clara e objetiva transformar qualquer conteúdo em um simples contexto, falha que a diferencia do docente.

$\mathrm{Na}$ Tabela 2, destacam-se três competências que precisam ser trabalhadas: a condução de reuniões, resolver problemas e tomada de decisão consensual, para que não haja desmerecimento, por um erro, as opiniões dos outros (discentes) separa claramente qual dos profissionais se aproxima mais do método ABP.

Tabela 2. Resumo das Avaliações - Docente B

\begin{tabular}{lcc}
\hline TÓPICOS ABORDADOS & EU & OS OUTROS \\
\hline Condução de reuniões & 4,71 & 2,86 \\
Gerenciamento de conflito & 4,77 & 3,07 \\
Liderança de grupo & 4,16 & 3,15 \\
Resolver problemas & 5,00 & 2,94 \\
Tomada de decisão consensual & 4,87 & 2,95 \\
Trabalho em equipe & 4,66 & 3,06 \\
Tomada de decisão & 4,36 & 3,40 \\
Análise crítica & 4,33 & 3,21 \\
Comunicação & 4,20 & 3,08 \\
\hline
\end{tabular}

\section{CONCLUSÃO}

A utilização do método de Aprendizagem Baseado em Problema exige dedicação e esforço para sua montagem e supervisão, na somatória, acaba liberando tempo para as atividades de investigação e laboratório, tantas vezes tornadas impossíveis pela rotina das atividades disciplinares. De acordo com Lopes et al. [11] "É importante também ressaltar que métodos como a $\mathrm{ABP}$, integrando com o uso do laboratório, podem ter um papel relevante nas escolas, 
constituindo o laboratório de aulas práticas num espaço de maior integração entre o ensino experimental e o ensino teórico, tornando a aprendizagem mais relevante, motivadora e acessível aos estudantes". Para os alunos, até onde se pode constatar, traz a vantagem que eles apreciam com evidente satisfação psicológica de serem participantes ativos de seu processo de aprendizagem.

As principais competências identificadas no docente A foram a condução de reuniões, comunicação, trabalho em equipe, entretanto existem pontos a serem potencializados como: análise crítica, tomada de decisão consensual e gerenciamento de conflito. E que as competências a serem potencializadas no docente B para o uso da ABP são: condução de reuniões, resolução de problemas e tomada de decisão consensual. Segundo Maseto [12], as competências abordadas como falhas no trabalho mostram as dificuldades estruturais, profissionais e pessoais de cada docente avaliado, criando um ciclo de problemas absorvidos pelo método podendo ser solucionados através do uso da ABP.

Entretanto, ainda se faz necessário o desenvolvimento de novos estudos que envolvam a implantação dessa metodologia, a avaliação dos resultados obtidos e a capacitação de docentes para atuarem com essas estratégias de ensino e aprendizagem nas instituições de ensino superior.

\section{REFERÊNCIAS BIBLIOGRÁFICAS}

1. Gil AC. Didática do ensino superior. São Paulo, Atlas, 2009, 177p.

2. Melo RC. Estratégias de ensino e aprendizagem baseadas em problemas (PBL) no ensino tecnológico, 2013.

3. Herreid CF. What is a case? Journal of College Science Teaching, 1997;27(2):92-94.

4. Ribeiro LR. Aprendizagem baseada em problemas (PBL): uma experiência no ensino superior, São Carlos, Eufsc, 2008.

5. Sá LP. Queiroz SL. Estudo de caso no ensino de química, São Paulo, 2. ed., Átomo, 2010.

6. Guimarães, C. C. Experimentação no ensino de química: caminhos e descaminhos rumo à aprendizagem significativa, Química Nova na Escola, 2009;31(3):198-202.

7. Costa A. Desenvolver a capacidade de argumentação dos estudantes: um objetivo pedagógico fundamental. Revista Iberoamericana de Educación, 2008;5(46):1-8.

8. Andrade MABS. Possibilidades e limites da Aprendizagem Baseada em Problemas no ensino médio. [Dissertação Mestrado em Educação para a Ciência] - Faculdade de Ciência da UNESP, Bauru, 2007.

9. Santos WLP, Mortimer EF. Tomada de decisão para ação social responsável no ensino de ciências, Ciência \& Educação 2001;7(1):95-111.

10. Macambira PMF. A aprendizagem baseada em problemas (ABP): uma aplicação na disciplina Gestão empresarial do curso de engenharia civil. Dissertação (Mestrado) - Universidade Federal do Pará, Instituto de Tecnologia, Programa de Pós-Graduação em Engenharia Civil. Belém, 2011.

11. Lopes RM, Silva-Filho MV, Marsden M, Alves NG. Aprendizagem baseada em problemas: uma experiência no ensino de química. 2011, Química Nova na Escola, 34:1275-1280.

12. Maseto MT. Competências pedagógicas do professor universitário. 2. ed. São Paulo, Summus, 2012. 